\title{
ОРГАНИЗАЦИЯ САМОСТОЯТЕЛЬНОЙ РАБОТЫ КУРСАНТОВ В ВОЕННЫХ ОБРАЗОВАТЕЛЬНЫХ ОРГАНИЗАЦИЯХ ВЫСШЕГО ОБРАЗОВАНИЯ ВОЙСК НАЦИОНАЛЬНОЙ ГВАРДИИ РОССИЙСКОЙ ФЕДЕРАЦИИ
}

\section{THE ORGANIZATION OF CADETS' \\ SELF-STUDY IN MILITARY EDUCATIONAL ORGANIZATIONS OF HIGHER EDUCATION OF THE NATIONAL GUARD OF THE RUSSIAN FEDERATION}

S. Jaranov

Summary: Cadets'self-study is an integral part of educational activities of military educational organizations of higher education of the National Guard of the Russian Federation and has a purpose to consolidate and deepen knowledge, skills and habits, to search and acquire new knowledge, to do training exercise, to study for upcoming classes, tests and exams. The need to organize cadets' self-study is determined by the fact that it is able to decide the issue between translation of knowledge and its learning in the connection of theory and practice.

Currently the requirements for the personal qualities of cadets of military educational organizations of higher education of the National Guard of the Russian Federation are ability to replenish and update knowledge, to search for the necessary materials themselves and to be a creative person. The orientation of the educational process to a self-developing person makes impossible to study without accounting cadets' individual and personal characteristics and giving them the right to choose ways and methods of study.

In the scientific article we will consider self-study of cadets of military educational organizations of higher education of the National Guard of the Russian Federation as an educational activity, organized by the teaching staff to achieve a didactic purpose and to do a set of tasks in a specially reserved time.

Keywords: self-study, cadet, knowledge, skills, habits, consultation.

\author{
Яранов Сергей Анатольевич \\ Дочент, ФГКВОУ ВО «Пермский военный институт войск \\ начиональной гвардии Российской Федерации» \\ jaranov.s@mail.ru
}

Аннотация: Самостоятельная работа курсантов является составной частью учебной деятельности военных учебных заведений высшего образования войск национальной гвардии России и преследует цель закрепить и углубить полученные знания, умения и навыки, научить осуществлять поиск новых знаний, а также выполнять учебные задания, готовиться к будущим занятиям, зачетам и экзаменам. Необходимость организации самостоятельной работы курсантов связана с тем, что благодаря этому может быть решено противоречие между получением знаний и их усвоением в неразрывной взаимосвязи теории и практики.

В настоящее время актуальными становятся требования к личным качествам курсантов военных учебных заведений высшей школы войск национальной гвардии России, которые заключаются в развитии умений самостоятельно накапливать и обновлять знания, проводить поиск необходимой литературы, развивать в себе творческую личность. Ориентировка образовательного процесса на самодостаточную, постоянно развивающуюся личность предопределяет необходимость учета индивидуально-личностных особенностей слушателей, а также предоставление им права самостоятельного выбора способов и методов обучения.

В научной статье самостоятельную работу курсантов военных учебных заведений высшей школы войск национальной гвардии России будем рассматривать как активную познавательную деятельность, организованную профессорско-преподавательским составом и направленную на достижение дидактической цели и выполнение комплекса заданий в специально отведенное для этого время.

Ключевые слова: самостоятельная работа, курсант, знания, умения, навыки, консультация.

\section{Введение}

$\mathrm{B}$ условиях глубоких преобразований, происходящих в войсках национальной гвардии РФ, предопределяющих необходимость обеспечения высокого уровня способностей офицеров на высоком уровне реализовывать свои интеллектуальные возможности в служебной деятельности. В данном контексте не подлежит сомнению тот факт, что подготовка и обучение военного специалиста должны способствовать самостоятельному развитию творческих способностей личности, активному овладению передовыми способами и методами опе- ративного и целенаправленного отбора необходимых данных, генерированию идей и поиску решений проблемных задач в нестандартных условиях несения военной службы.

Саморазвитие курсантов - вот тот ориентир учебного процесса, который делает обучение возможным только при условии учета индивидуальных особенностей личности, предоставления ей права на выбор путей и способов обучения. Таким образом, воспитать компетентную личность, которая будет нацелена на будущее, сможет решать стандартные проблемы исходя из полу- 
ченного опыта учебы и адекватной оценки конкретной ситуации, становится новой задачей образовательного процесса.

Обязательные условия решения этих задач: повысить роль самостоятельной работы курсантов над учебным материалом; усилить ответственность преподавателя за развитие у обучающихся навыков самостоятельной работы; стимулировать профессиональный рост курсантов; воспитывать их творческую активность и инициатиBy.

Учебные программы, где доля самостоятельной работы соответствует требованиям нормативных правовых документов, при внедрении в практику активно способствуют модернизации учебного процесса.

\section{Шель исследования}

Самостоятельную работу курсантов высших военных учреждений образования войск национальной гвардии России (ВООВО ВНГ РФ) мы будем рассматривать как активную познавательную деятельность, организованную профессорско-преподавательским составом для достижения дидактической цели и выполнения в специально отведенное для этого время (время, отведенное для обязательной самостоятельной подготовки курсантов) комплекса заданий.

Стандарт высшего образования в ВООВО ВНГ РФ предполагает, что выпускник будет обладать глубокими теоретическими знаниями по фундаментальным дисциплинам, которые понадобятся ему при усвоении дисциплин, формировании умений и навыков в эксплуатации военной и специальной техники, находящейся на вооружении войск.

Обучение курсантов представляет собой социальнопедагогический процесс, который обусловлен запросами страны в хорошо обученных и подготовленных специалистах, способных успешно и эффективно выполнять боевые задачи, а также самостоятельно и ответственно принимать решения.

Не обладая творческим подходом к делу и высокой самостоятельностью курсант не способен успешно овладеть учебным материалом. В связи с этим ключевая задача ВООВО ВНГ РФ заключается в такой организации учебного процесса, которая позволит максимально развить мыслительную деятельность курсантов, сформировать у них навыки самостоятельной работы, т.к. ключевой целью обучения слушателей является научить их самостоятельно действовать.

\section{Материал и методы исследования}

В ВООВО ВНГ РФ существуют следующие основные виды учебных занятий: лабораторные работы, семинары, лекции, контрольные работы, практические занятия, индивидуальные собеседования, групповые упражнения, курсовые работы (курсовое проектирование), тактические (тактико-специальные) занятия и учения, самостоятельная работа обучающихся, практика, консультации. Кроме того, дополнительно осуществляются и другие виды учебных занятий, которые вводятся согласно решению руководителя ВООВО ВНГ РФ после обсуждения на ученом совете [1].

Самостоятельная работа обучающихся как составная часть учебной деятельности проводится для закрепления и углубления полученных знаний, умений и навыков, ее цель - поиск и приобретение новых знаний, в том числе с использованием автоматизированных обучающих курсов (систем). Самостоятельная работа обучающихся способствует выполнению учебных заданий, подготовке к предстоящим занятиям, зачетам и экзаменам.

Организация самостоятельной работы обучающихся возлагается на командиров подразделений курсантов, ее методическое обеспечение - на кафедры. Распорядок дня предусматривает ежедневное, кроме предвыходных и предпраздничных дней, время на самостоятельную работу из расчета три академических часа.

Систематический контроль за организацией самостоятельной работы курсантов осуществляет учебный отдел ВООВО ВНГ РФ, анализ его результатов производится не реже одного раза в месяц.

Самостоятельной работой курсантов руководит профессорско-преподавательский состав, проводится она в отведенные часы в соответствии с расписанием занятий, ее объем не превышает 10 процентов от отводимого на изучение дисциплины (модуля) учебного времени. Самостоятельная работа заключается в написании рефератов, расчетно-графических и вычислительных работах, моделировании и других творческих заданиях, которые соответствуют рабочей программе (тематическому плану) изучения дисциплины (модуля). Занятия данного вида своей основной целью предполагают обучение курсантов методам самостоятельной работы с учебным материалом.

Одна из форм руководства самостоятельной работой курсантов, чтобы оказывать им помощь в освоении учебного материала, - консультации. Проводят их регулярно в часы, отведенные для самостоятельной работы, в основном они индивидуальные. Если имеется необходимость, в том числе перед семинарами, практически- 
ми, тактическими (тактико-специальными) занятиями и учениями, индивидуальными собеседованиями, контрольными работами, экзаменами (зачетами), проводятся групповые консультации.

Самостоятельная работа курсантов организуется на кафедрах ВООВО ВНГ РФ после лекций, групповых занятий перед семинарами, практическими занятиями, групповыми упражнениями, промежуточной аттестацией, а также по мере необходимости. Руководитель занятия обеспечивает методическое сопровождение и контроль проведения самостоятельной работы.

Самостоятельная работа курсантов обеспечивается специальной литературой, методическими указаниями, компьютерными программами и возможностью использования Интернета. При необходимости может использоваться оборудование лабораторий и компьютерных (терминальных) классов.

\section{Результаты исследования и их обсужление}

В процессе достижения учебных и практических целей, в ходе подготовки военных специалистов ключевое усилие, по моему мнению, следует сконцентрировать на развитие творческого мышления и самостоятельности курсантов, их способности быстро приспосабливаться в конкретной служебно-боевой (боевой) обстановке, хорошо в ней ориентироваться, принимать обоснованные и взвешенные решения, не терять самообладание в критических ситуациях.

К функциям самостоятельной работы можно отнести:

1. Развивающую: культура умственного труда курсантов повышается, они приобщаются к творческим видам деятельности, обогащают свои интеллектуальные способности.

2. Информационно-обучающую: результативность учебной деятельности курсантов на аудиторных занятиях повышается.

3. Ориентирующую и стимулирующую: процесс обучения курсантов получает профессиональное ускорение.

4. Воспитывающую: профессиональные качества курсантов как специалистов формируются и получают развитие.

5. Исследовательскую: курсанты выходят на новый уровень профессионального и творческого мышления.

Самостоятельность, творческая направленность, планирование своей работы, а также личностно-деятельностный подход - вот принципы, которые лежат в основе самостоятельной работы курсантов [2, 3].

Самостоятельная работа обучающихся преследует следующие цели:

- закрепить полученные курсантами теоретические знания и практические умения и систематизировать их;

- углубить и расширить их теоретические знания;

- научить пользоваться нормативными правовыми документами, а также учебной и специальной литературой;

- развивать способности курсантов к познаванию, их активность и исследовательские умения: творческую инициативу, самостоятельность, ответственность и организованность;

- формировать у обучающихся самостоятельное мышление, стимулировать их саморазвитие, самосовершенствование и самореализацию.

Достижение курсантами указанной цели возможно лишь при условии решения на основе плана самостоятельной работы следующих задач:

- изучение рекомендованных нормативных правовых документов и иных источников;

- освоение представленных в глоссарии основных понятий;

- ответы на контрольные вопросы;

- решение проверочных задач, кейсов и ситуаций (выбор решения в должности командира подразделения, начальника войскового наряда на выполнение поставленной служебно-боевой (боевой) задачи);

- выполнение контрольных, лабораторных и курсовых работ (курсового проектирования).

Основные элементы, из которых в основном складывается работа курсантов, заключаются:

- в изучении согласно учебному плану программного материала по всем учебным дисциплинам и его усвоении;

- разработке боевых графических документов и расчетно-графических работ;

- выполнении письменных контрольных, лабораторных и курсовых работ (курсового проектирования);

- подготовке курсовых работ (курсового проектирования), подготовке к зачетам, итоговым экзаменам и их сдаче;

- написании дипломной работы и ее защите.

Формами самостоятельной работы курсантов могут быть:

выполнение заданий, в конце каждого занятия получаемых от профессорско-преподавательского состава; это важно для закрепления и расширения знаний;

- конспектирование лекций и групповых занятий;

- индивидуальные и групповые консультации, на которых курсантам разъясняются вопросы изуча- 
емой дисциплины;

- подготовка к семинарам;

- подготовка к промежуточной и итоговой аттестации;

- подготовка к занятиям, проводимым с использованием активных форм обучения (круглые столы, деловые игры, конференции);

- выполнение контрольных, лабораторных, курсовых и дипломных работ (курсового проектирования);

- написание научных докладов, рефератов, эссе;

- анализ ситуаций по действиям подразделений, войсковых нарядов в ходе выполнения служебнобоевых (боевых) задач и при осложнении обстановки (мини-кейсов) и др.

Самостоятельная работа курсантов может выполняться в виде таких заданий, как:

а) в целях получения знаний:

- чтение текста, что подразумевает нормативные правовые документы, учебники и учебные пособия, а также дополнительную литературу;

- составление плана текста (ответа);

- графическое изображение с помощью условных знаков оперативной обстановки ВНГ РФ схем, нанесение решения на рабочую карту командира (начальника) на основе тактического задания и боевого распоряжения вышестоящего начальника;

- конспектирование;

- выписки из текста;

- работа со словарями, справочниками, сборниками;

- исследовательская (военно-научная) работа;

- использование аудио- и видеозаписи;

- работа с электронными информационными ресурсами и ресурсами Интернета;

б) в целях закрепления и систематизации полученных знаний:

- обработка текста, то есть работа с конспектом лекций, групповых занятий;

- повторная обработка нормативных правовых документов, учебников и учебных пособий, дополнительной литературы, аудио- и видеозаписей;

- написание плана и тезисов ответа;

- составление альбомов, схем, таблиц, ребусов, кроссвордов для систематизации учебного материала;

- выполнение тестовых заданий;

- ответы на контрольные вопросы;

- аннотирование, реферирование, рецензирование текста;

- написание (оформление) пояснительной записки к решению командира (начальника) на выполне- ние служебно-боевой (боевой) задачи;

- написание эссе;

- подготовка сообщений к выступлению на семинаре, конференции;

- подготовка рефератов, докладов;

- составление глоссария, кроссворда или библиографии по конкретной теме;

- работа с компьютерными программами;

- подготовка к зачетам и экзаменам;

- подготовка к защите преддипломной практики и к защите дипломной работы;

в) в целях получения умений:

- решение по образцу задач и упражнений;

- решение вариативных задач и упражнений;

- составление чертежей, схем;

- выполнение расчетно-графических работ и боевых графических документов;

- решение ситуационных служебно-боевых (боевых) задач;

- подготовка к деловым играм;

- участие в научных и практических конференциях;

- организация выставок;

- проектирование и моделирование разных видов и компонентов служебно-боевой деятельности;

- создание проспектов, проектов, моделей;

- составление памяток, рекомендаций, советов, кодексов;

- экспериментальная работа, участие в военно-научном обществе курсантов;

- участие в рационализаторской и изобретательской работе на кафедрах ВООВО ВНГ РФ;

- рефлексивный анализ профессиональных умений с использованием аудио- и видеотехники, компьютерных расчетных программ и электронных практикумов;

- подготовка курсовых и дипломных работ (курсового проектирования).

Перед тем как начать освоение конкретной дисциплины, курсанту следует ознакомиться внимательно с методическими указаниями (рекомендациями) для обучающихся и требованиями программы по данному курсу. Методические указания или рекомендации для курсантов являются приложениями к программе дисциплины и призваны детально раскрывать рекомендуемый порядок и характер разных видов учебной, а также самостоятельной работы [4].

К направляющим самостоятельную работу курсантов методическим материалам относятся:

- сборники основных образовательных программ по специальности;

- методические указания к групповым упражнениям, семинарским, лабораторным и практическим занятиям; 
- примеры решения заданий, оформления рабочих тетрадей и отчетов по лабораторным и расчетным работам, оформления расчетно-графических работ и боевых графических документов, использования электронных информационных ресурсов, то есть часть учебно-методического комплекса по дисциплине;

- методические указания по выполнению курсовых и дипломных работ (курсового проектирования);

- списки основной и дополнительной литературы в рабочей программе дисциплины.

Методические указания (рекомендации) для обучающихся привлекают внимание курсанта к сути изучаемой дисциплины, учат уметь анализировать события и факты, переходить от теории к практической части, а также облегчают подготовку к контрольным, лабораторным, курсовым работам (курсовому проектированию) и зачетам и экзаменам.

Условием эффективности всей самостоятельной работы курсантов является прежде всего их уровень самоконтроля. Объектом самоконтроля здесь являются: планирование самостоятельной работы и следование индивидуальному плану; изучение дисциплины в соответствии с тематическим планом и учебной программой; выполнение контрольных, лабораторных, расчетно-графических, курсовых и дипломных работ (курсового проектирования).

Самостоятельную работу курсанты могут выполнять как индивидуально, так и группами, что зависит от цели, объема, конкретной тематики, уровня сложности самостоятельной работы, а также имеющихся у курсантов умений.

Обобщая различные подходы к определению «самостоятельная работа», можно сказать, что это специфическая педагогическая конструкция. Некорректно и нецелесообразно воспринимать усвоение знаний в качестве простого процесса передачи знаний от учителя к ученику без учета особенностей мыслительной деятельности обучающегося. Не подлежит сомнению тот факт, что получение знаний, освоение материала без активного включения самого курсанта невозможно. Для повышения продуктивности самостоятельной работы курсанту следует работать над собой, овладевать методологией самообразовательной деятельности, воспитывать в себе такие качества, как ответственность, внимание, настойчивость и находчивость в преодолении трудностей, мобильность, развивать умение работы с нормативными правовыми документами, конспектами, исполнение боевых графических документов, в конечном итоге свою конкурентоспособность и карьерную успешность.

Этапы организации самостоятельной работы следу- ющие:

- составление плана самостоятельной работы курсанта по дисциплине;

- разработка и выдача заданий для самостоятельной работы;

- проведение индивидуальных и групповых консультаций по выполнению заданий;

- контроль выполнения и результата самостоятельной работы курсанта.

Совершенствование самостоятельной работы курсантов дает основания для качественных изменений в учебном процессе ВООВО ВНГ РФ. Однако необходимы выявление системных факторов в ее организации, непосредственно связанных с деятельностью ВНГ РФ, и глубокая индивидуализация учебного процесса, основанная на особенностях интеллекта курсантов [5].

Таким образом, важными направлениями в формулировании и решении проблемы организации самостоятельной работы курсантов являются:

- повышение роли самостоятельной работы в образовательном процессе ВООВО ВНГ РФ;

- увеличение внимания к самостоятельной работе по мере усложнения системы образования;

- переход к целостным технологиям самостоятельной работы;

- выявление, изучение, обобщение опыта самостоятельной работы в ВООВО ВНГ РФ.

\section{Зак^ючение}

Исключительно велики значение и роль самостоятельной работы обучающихся в современных условиях к будущей профессиональной деятельности. Постоянное совершенствование вооружения, боевой и специальной техники в интересах выполнения задач, стоящих перед ВНГ РФ, поставили перед ВООВО ВНГ РФ комплексную и важную задачу, которая заключается в том, чтобы в ограниченный временных рамках обучения подготовить высококвалифицированного, профессионального специалиста, который умеет самостоятельно усваивать знания, способен в короткие сроки приобретать навыки работы с новыми образцами вооружения, военной и специальной техникой, следить за передовыми достижениями военного дела. Эту задачу можно успешно решить благодаря постоянному совершенствованию всего учебного процесса, основой которого является самостоятельная работа курсантов.

Требования к высококвалифицированному военному специалисту обуславливают создание таких условий подготовки в процессе обучения, приоритетом которых является формирование разносторонне развитой личности - офицера войск национальной гвардии РФ. 


\section{ЛИТЕРАТУРА}

1. Приказ Росгвардии от 07.11.2017 № 466 «06 утверждении Порядка организации и осуществления образовательной деятельности по основным профессиональным образовательным программам, реализуемым в интересах обороны и безопасности государства, обеспечения законности и правопорядка в военных образовательных организациях высшего образования войск национальной гвардии Российской Федерации» (зарегистрировано в Минюсте России 29.11.2017 № 49038) // Российская газета. 2017. 5 дек.

2. Морева Н.А. Технологии профессионального образования. М.: Издательский центр «Академия», 2007. 432 с.

3. Пидкасистый П.И. Педагогика. М. : Издательство Юрайт, 2016. 408 с.

4. Белогурова В.А. Научная организация учебного процесса. М.: ГЭОТАР-Медиа, 2010. 511 с.

5. Куклина Е.Н. Организация самостоятельной работы студента. М.: Издательство Юрайт, 2019. 235 с.

๑) Яранов Сергей Анатольевич (jaranov.s@mail.ru).

Журнал «Современная наука: актуальные проблемы теории и практики»

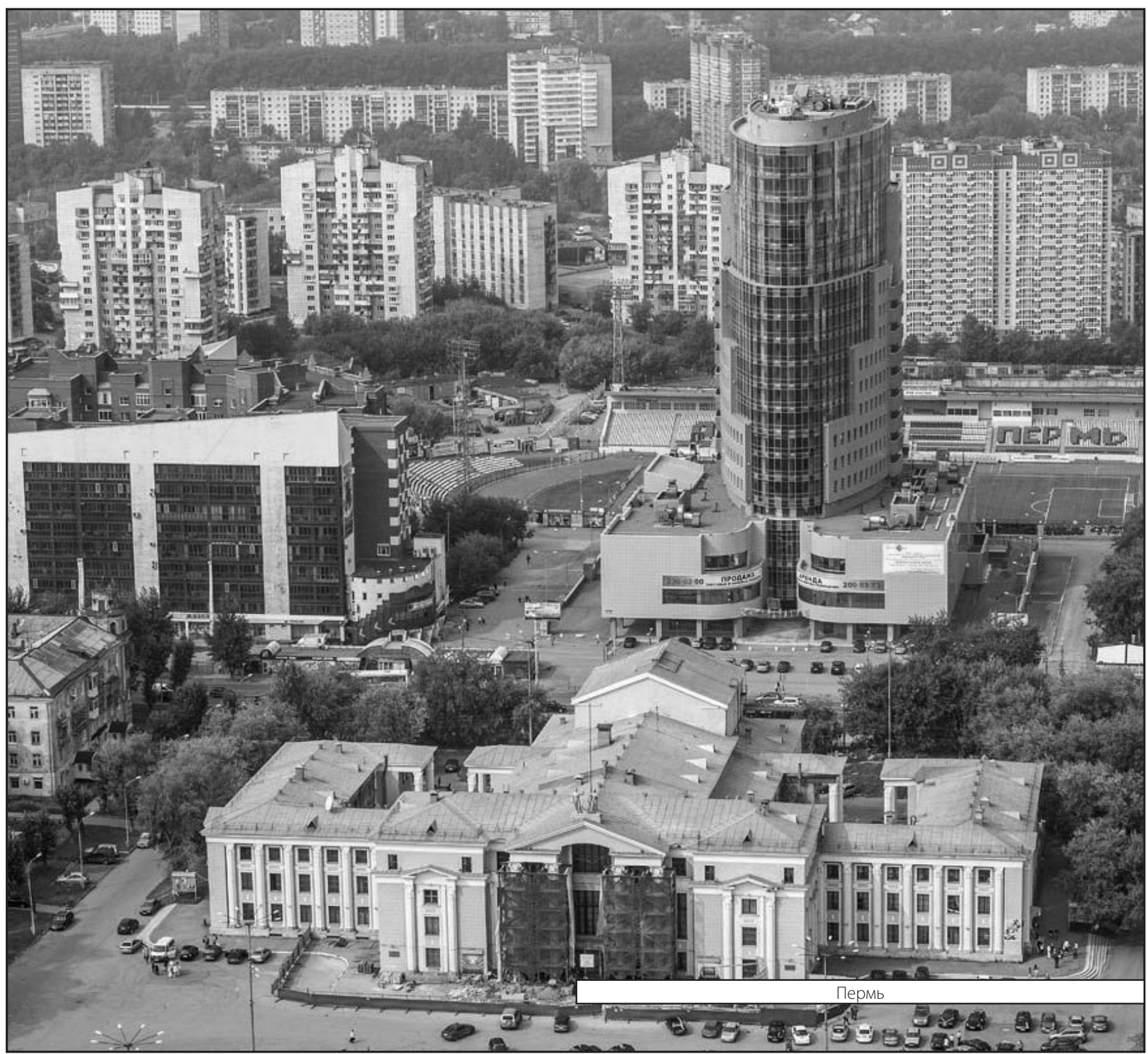

